\title{
AVALIAÇÃO DA QUALIDADE DAS SEMENTES DE Moringa oleifera LAM. DURANTE O ARMAZENAMENTO
}

\author{
Evaluation of quality of the drumstick seeds during the storage
}

\author{
Antonio Marcos Esmeraldo Bezerra', Sebastião Medeiros Filho², \\ João Batista Santiago Freitas ${ }^{3}$, Elizita Maria Teófilo ${ }^{4}$
}

\begin{abstract}
RESUMO
A moringa (Moringa oleifera Lam.; Moringaceae), espécie perene originária do noroeste indiano, que se adapta tanto às condições irrigadas quanto às de sequeiro, pouco exigente em solos e fertilizantes, encontra-se disseminada na região nordeste, particularmente no Ceará, graças à sua utilização na clarificação de águas turvas. A despeito do seu reconhecido valor medicinal e como hortaliça não-convencional rica em vitamina A, ainda carece de estudos que focalizem a viabilidade das sementes durante o armazenamento. Baseado nessa premissa, conduziu-se um ensaio com os tratamentos dispostos num arranjo fatorial $2 \times 4$, correspondendo à combinação de dois ambientes (natural e câmara fria) e quatro tempos de armazenamento (0, 6, 12 e 24 meses), segundo um delineamento inteiramente casualizado com quatro repetições. As amostras de sementes correspondentes aos tratamentos investigados foram acondicionadas em garrafa plásticas tipo PET de $600 \mathrm{~mL}$. As variáveis de observação foram: teor de água, germinação, comprimento da raiz, massa seca de plântula e condutividade elétrica. Pela análise dos resultados, evidenciou-se que, aos 12 meses de armazenamento em embalagem plástica sob ambiente natural, as sementes perdem a sua viabilidade, enquanto na câmara aos 24 meses, as sementes apresentam redução na qualidade fisiológica.
\end{abstract}

Termos para indexação: Moringa oleifera, germinação, vigor, estocagem.

\begin{abstract}
Drumstick (Moringa oleifera Lam., Moringaceae) is a perennial species originating from the indian northwest that adapts to both irrigated and rain fed crop conditions and it is not very demanding on soils and fertilizers. It is grown in the brazilian northeast, specially in Ceará State, due to its use in clarification of cloudy waters. In spite of its recognized medicinal value and as non conventional vegetable rich in vitamin A no studies focalizing the viability of the seeds during the storage have been done. So, an experiment was carried out treatments arranged in a fatorial $2 \times 4$ scheme, corresponding the combination of two environments (natural and cold storage) and four times of storage (0, 6, 12 and 24 months) according to an entirely randomized design with four repetitions. The samples of seeds corresponding to the investigated treatments were conditioned in plastic bottle (PET $600 \mathrm{~mL}$ ). The measuring variables were: water content; percentage of germination; length of root, dry matter of seedling and electrical conductivity. The analysis of the results evidenced that after 12 months of storage in plastic bottles under natural environment, the seeds lose its viability, while under cold storage for 24 months the seeds present a reduction in its quality.
\end{abstract}

Index terms: Moringa oleifera, Moringaceae, seeds, storage, viability.

(Recebido para publicação em $1^{\circ}$ de abril de 2004 e aprovado em 20 de setembro de 2004)

\section{INTRODUÇÃO}

A moringa é uma espécie perene, originária do noroeste indiano, que pode ser explorada tanto em condições irrigadas como de sequeiro, apresentando um grande potencial em face de sua multiplicidade de usos - alimentar, agrícola, medicinal e industrial (RAMACHANDRAN et al., 1980; CORREA, 1984; MATOS e ABREU, 1998; SILVA e KERR, 1999; LORENZI e MATOS, 2002). As sementes são ricas em proteínas (33,9\%) e lipídeos (37,2\%) (MACHADO e CARNEIRO, 2000), requerendo estudos direcionados à sua exploração comercial
(OLIVEIRA et al., 1999). O óleo extraído das sementes de Moringa oleifera var. PKM 1 apresenta alta resistência à oxidação e contém elevados teores de ácidos graxos insaturados, especialmente o oléico (71,6\%), sendo o palmítico e o behênico (ambos com $6,4 \%$ os ácidos graxos saturados dominantes (LALAS e TSAKINS, 2002).

Minimizando-se os fatores que reduzem a qualidade fisiológica das sementes na fase de campo (adversidades após a maturação fisiológica e antes da colheita) e durante as operações de colheita, secagem e beneficiamento, a preservação da qualidade depende das condi-

1. D.Sc., Professor Adjunto, Departamento de Planejamento e Política Agrícola, CCA/UFPI, Campus da Socopo, 64049-550 - Teresina, PI. esmeraldo@ufpi.br.

2. D.Sc., Professor Adjunto, Departamento de Fitotecnia, UFC, Caixa Postal 12168 - 60356-001 - Fortaleza, CE. filho@ufc.br

3. Engenheiro Agrônomo, M.Sc., Doutorando em Bioquímica pela UFC. batistola@bol.com.br

4. Engenheira Agrônoma, D.Sc., Laboratório de Análise de Sementes; Departamento de Fitotecnia, UFC, elizita@ufc.br 
ções de armazenamento da semente (POPINIGIS, 1985). A umidade relativa e a temperatura são os principais fatores externos que influenciam a longevidade das sementes (COPELAND, 1976), sendo as condições ambientais de baixa temperatura $\left(\leq 10^{\circ} \mathrm{C}\right)$ e baixa umidade relativa (50-60\% de UR) consideradas adequadas à manutenção da viabilidade durante o armazenamento. Vários autores observaram decréscimos na viabilidade e no vigor das sementes durante o período de armazenamento das sementes (ARRIGONI-BLANK et al., 1997; MACEDO et al., 1998; CORVELLO et al., 1999; FREITAS et al., 2000; PÁDUA e VIEIRA, 2001), atribuindo-se essa redução na qualidade fisiológica às transformações degenerativas características da deterioração (POPINIGIS, 1985). Trabalhos específicos sobre armazenamento de sementes de moringa trazem resultados controvertidos. Assim, Palanisamy et al. (1985) constataram que a viabilidade decresce progressivamente com o avanço no tempo de estocagem, sendo esse decréscimo menos acentuado em sementes tratadas com captan e embaladas em sacos de polietileno, cuja germinação, após 12 meses (40,0\%), foi superior às submetidas aos demais tratamentos (argila ativada; carbendazim e cinza de esterco), cujos valores da porcentagem de germinação situaram-se na faixa de $4,0-14,0 \%$. Por sua vez, Cáceres et al. (1991) verificaram que o poder germinativo de sementes de alta qualidade, provenientes de bancos naturais, foi da ordem de $92-94 \%$, aos 9 meses, e de 78\%, aos 12 meses. Silva e Kerr (1999) observaram que a porcentagem de germinação nas condições indianas declinou, significativamente, com o tempo de estocagem (1 mês - 60\%; 2 meses $48 \%$ e 3 meses $-7,5 \%$ ), enquanto, na Guatemala, o poder germinativo foi preservado por um período de 7 meses (94\%). Teófilo et al. (2003) demonstraram que sementes de moringa, acondicionadas em garrafas plásticas, conservam a germinação e o vigor por seis meses, em ambiente natural, e por nove meses, em câmara fria.

Para obter informações acerca da preservação da qualidade fisiológica das sementes de moringa produzidas no Ceará, realizou-se esta pesquisa com o intuito de avaliar a viabilidade das sementes durante o armazenamento, em ambiente natural e câmara fria, por dois anos.

\section{MATERIAL E MÉTODOS}

O experimento foi conduzido no Laboratório de Análise de Sementes do Departamento de Fitotecnia do Centro de Ciências Agrárias da Universidade Federal do Ceará (UFC), no período de janei- ro/00 a fevereiro/02. As sementes, colhidas em novembro/99, foram de plantas matrizes cultivadas na Fazenda Experimental do Vale do Curu, em Pentecoste, Ceará, pertencente à UFC. Os tratamentos constituíram-se de um arranjo fatorial $2 \times 4$, representado por dois ambientes (natural - sem controle de temperatura e umidade e câmara fria $-10^{\circ} \mathrm{C} / 55 \%$ de umidade relativa-UR) e quatro tempos de armazenamento (0; 6; 12 e 24 meses) dispostos segundo um delineamento inteiramente casualizado com quatro repetições. As amostras de sementes, correspondentes aos tratamentos, foram acondicionadas em garrafa plástica tipo PET de $600 \mathrm{~mL}$, armazenadas nos ambientes citados e, decorridos os períodos de tempo préestabelecidos, procederam-se às seguintes determinações:

a) teor de água - de cada uma das combinações de fatores testadas, quatro subamostras de 6,55 $\pm 0,15$ gramas de sementes foram acondicionadas em cápsulas de alumínio e conduzidas para estufa, regulada para $105 \pm 3^{\circ} \mathrm{C}$ durante 24 horas, sendo o teor de água determinado, portanto, pelo método da estufa como recomenda as Regras para Análises de Sementes (BRASIL, 1992);

b) porcentagem de germinação - quatro repetições de 25 sementes por tratamento foram postas para germinar em papel "Germitest" na forma de rolo previamente umedecido com água destilada, na proporção de 2,5 vezes o peso do papel. Os rolos foram dispostos no interior do germinador regulado para $25^{\circ} \mathrm{C}$, sendo a contagem das plântulas normais efetuada aos 10 dias para fins de avaliação da porcentagem de germinação;

c) comprimento da raiz - para obtenção dessa variável, utilizaram-se quatro repetições de 15 sementes/tratamento, que foram postas para germinar nas mesmas condições do teste de germinação, sendo a medição da raiz realizada nas plântulas normais com o auxílio de uma régua graduada em centímetros, 10 dias após a semeadura, seguindo a metodologia proposta por Popinigis (1985);

d) massa seca de plântula - das plântulas normais oriundas do tese de comprimento de raiz, retiraram-se os cotilédones e depois elas foram acondicionadas em sacos de papel e levadas para estufa regulada a $80^{\circ} \mathrm{C} / 24$ horas, para determinação da massa seca (mg plântula ${ }^{-1}$ ), segundo Nakagawa (1994);

e) condutividade elétrica - para determinação dessa variável, adotou-se a metodologia citada por Vieira e Krzyzanowski (1999). Quatro repetições de 25 sementes de cada tratamento foram pesadas em balança de 
precisão e depois colocadas em copos plásticos contendo $125 \mathrm{~mL}$ de água destilada. Em seguida, os copos foram colocados em germinador a $25^{\circ} \mathrm{C}$ por 24 horas e logo após procedeu-se à leitura das soluções contendo os lixiviados das sementes em um condutivímetro previamente calibrado, sendo os resultados expressos em $\mu \mathrm{S} / \mathrm{cm} / \mathrm{g}$ de semente.

Após a tabulação, as variáveis foram submetidas à análise de variância (FERREIRA, 1996) e quando a interação ambiente $\mathrm{x}$ tempo de armazenamento foi significativa, efetuou-se o desdobramento do fator tempo de armazenamento dentro de cada ambiente.

\section{RESULTADOS E DISCUSSÃO}

Pela análise da variância apresentada na Tabela 1 , revela-se a existência de interação ambiente $\mathrm{x}$ tempo de armazenamento em todas as variáveis, exceto na condutividade elétrica, na qual apenas o fator tempo de armazenamento foi significativo.

Observou-se um ajuste quadrático para o teor de água em função do tempo de armazenamento (Figura 1A). Nas sementes armazenadas em ambiente natural, o teor de água decresceu suavemente com o avanço no tempo de armazenamento, enquanto na câmara fria, a variação foi maior, cujos valores no intervalo de zero a seis meses situaram-se no mesmo patamar (8,8 e 8,6\%), caindo para 7,8 e 7,7\% nos períodos subseqüentes (12 e 24 meses). Assim, verificase que o teor de água da semente foi mantido em níveis aceitáveis ao armazenamento em embalagem impermeável. Arrigoni-Blank et al. (1997) constataram que o teor de água inicial das sementes $(9,9 \%)$ de casaqueira (Campomanesia rufa), acondicionadas em sacos de polietileno, caiu em 3,31 e 4,41\%, depois de um mês de armazenadas em ambiente natural e refrigerado, respectivamente, estabilizando-se entre 6 e $7 \%$ nos quatro períodos de armazenamento estudados (30, 60, 80 e 180 dias). Corvello et al. (1999) observaram que o teor de água das sementes de cedro ( $\mathrm{Ce}$ drella fissilis) colhidas 35 semanas após a antese aumentou com o tempo de armazenamento, tanto em ambiente refrigerado $\left(5 \pm 2{ }^{\circ} \mathrm{C} / 60 \pm 5 \%\right.$ de UR) como no ambiente natural. Teófilo et al. (2003) observaram que o teor médio de água das sementes de moringa embaladas em garrafa plástica e armazenadas durante três períodos (3, 6 e 9 meses) em ambiente natural e câmara fria foram iguais a 8,13 e 7,72\%, respectivamente, portanto, semelhantes aos observados nesta pesquisa.

Evidencia-se na Figura $1 \mathrm{~B}$ que houve uma resposta quadrática da porcentagem de germinação em função do tempo de armazenamento. No armazenamento em câmara fria (Figura 1B), o poder germinativo das sementes de moringa foi mantido por 12 meses (85\%), verificando-se uma queda na qualidade aos 24 meses (71\%). Nas mesmas condições testadas no ensaio, Teófilo et al. (2003) notaram que sementes de moringa preservam o poder germinativo inicial por nove meses. Também Medeiros Filho et al. (1996) observaram que sementes deslintadas de algodão mantêm o poder germinativo por cinco meses, quando armazenadas na câmara fria $\left(12^{\circ} \mathrm{C} / 50 \%\right.$ de UR). Em ambiente natural (Figura $1 \mathrm{~B})$, as sementes conservaram a sua porcentagem de germinação inicial (84\%) por seis meses (81\%), observando-se uma redução significativa dessa variável aos 12 (19\%) e 24 (0\%) meses de armazenamento. Na mesma espécie, Palanisamy et al. (1985) observaram que a porcentagem de germinação das sementes tratadas com captan após um ano de armazenamento foi em torno de $40 \%$, portanto, superior ao obtido nesta pesquisa. Macedo et al. (1998) constataram que a germinação de sementes de algodão aumentou de modo gradativo até o sexto mês de armazenamento em ambiente natural $\left(21,3^{\circ} \mathrm{C} / 72,5 \%\right.$ UR), devido à dormência manifestada nas sementes recém-colhidas, e a partir do oitavo mês, ocorreu um declínio progressivo, atingindo o valor mínimo aos 12 meses de estocagem. Pádua e Vieira (2001) verificaram que sementes de algodão com alto nível de vigor (87\% de germinação inicial) apresentaram germinação acima dos padrões mínimos (60-70\%) até 10 meses de armazenamento em ambiente natural $\left(29,7^{\circ} \mathrm{C} / 41-76 \%\right.$ de UR). Confrontando-se os resultados dos dois ambientes de armazenagem percebe-se que, sob condições de baixa temperatura e umidade relativa, o potencial de armazenamento das sementes foi superior ao ambiente com alta temperatura e alta umidade relativa do ar. Esse resultado coaduna com Delouche et al. (1973), quando recomenda a temperatura de $10^{\circ} \mathrm{C}$ e $60 \%$ de umidade relativa do ar para manutenção da germinação de sementes oleaginosas (com umidade máxima de 9\%), em médio prazo (18 meses), nas regiões tropicais e subtropicais. 
TABELA 1 - Quadrados médios e coeficientes de variação (CV) relativos ao teor de água (TA), porcentagem de germinação (GER), comprimento de raiz (CR), massa seca de plântula (MSP) e condutividade elétrica (CE) obtidos em sementes de moringa armazenadas em dois ambientes (natural e câmara fria) por quatro períodos (0, 6, 12 e 24 meses). Fortaleza, CE, UFC, 2003.

\begin{tabular}{lcccccc}
\hline \multirow{2}{*}{ Fontes de Variação } & \multirow{2}{*}{ GL } & \multicolumn{5}{c}{ Quadrados Médios } \\
\cline { 3 - 7 } & & TA & GER & CR & MSP & CE \\
\hline Ambiente (A) & 1 & $2,46^{* *}$ & $10731,12^{* *}$ & $283,81^{* *}$ & $741,12^{* *}$ & 190,47 \\
Tempo de armazenamento (T) & 3 & $1,00^{* *}$ & $4820,46^{* *}$ & $134,73^{* *}$ & $2353,12^{* *}$ & $1842,20^{* *}$ \\
Interação AxT & 3 & $0,34^{* *}$ & $2747,79^{* *}$ & $95,76^{* *}$ & $317,12^{* *}$ & 179,74 \\
Resíduo & 24 & 0,06 & 503,00 & 1,62 & 1250,27 & 76,79 \\
\hline CV (\%) & - & 2,02 & 7,13 & 9,49 & 14,95 & 15,64 \\
\hline
\end{tabular}

**Valor de F significativo em nível de 1,0\% de probabilidade.

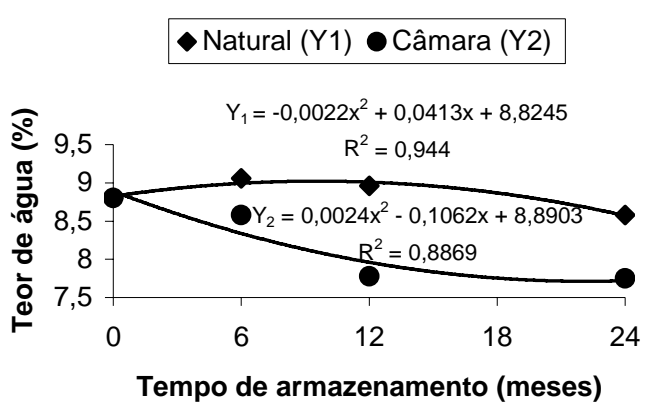

A

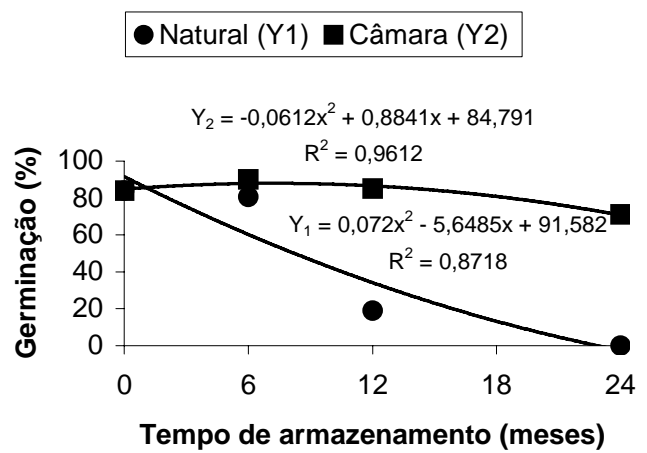

B

FIGURA 1 - Teor de água (A) e porcentagem de germinação (B) durante o armazenamento de sementes de moringa em ambiente natural e câmara fria. Fortaleza, UFC, 2003.

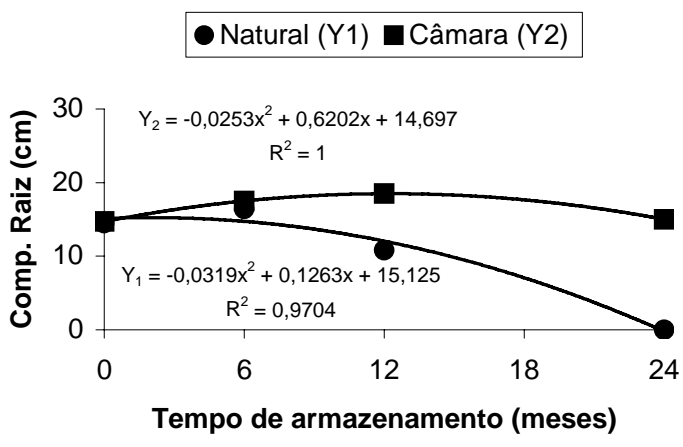

A

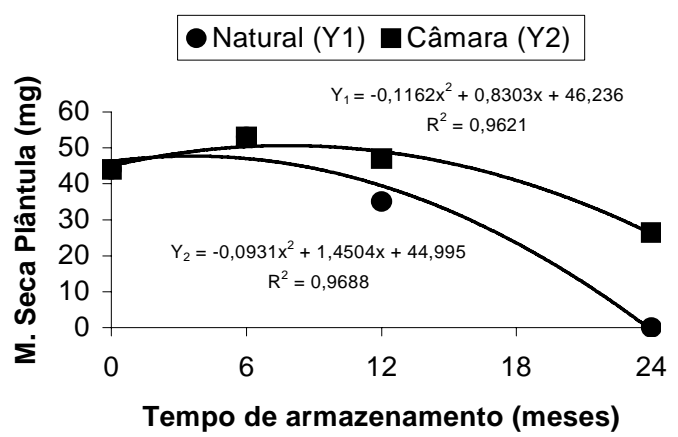

B

FIGURA 2 - Comprimento de raiz (A) e massa seca de plântula (B) avaliada durante o armazenamento de sementes de moringa em ambiente natural e câmara fria. Fortaleza, UFC, 2003. 
Para o parâmetro comprimento da raiz da plântula, exposto na Figura 2A, houve uma resposta quadrática com o decorrer do tempo de armazenamento. Esse teste direto de vigor revelou uma diminuição mais acentuada nas sementes armazenadas sob condições não controladas do que em câmara fria. No ambiente natural, constatou-se que o comprimento da radícula de zero a seis meses foi estatisticamente semelhante (14,5 e $16,4 \mathrm{~cm}$, respectivamente). Por sua vez, em câmara fria, o comprimento da radícula cresceu entre 0 e 12 meses $(14,5$ e 18,5 cm, respectivamente), observando-se um pequeno decréscimo aos 24 meses de armazenamento $(15,0 \mathrm{~cm})$.

A massa seca da plântula em função do tempo de armazenamento (Figura 2B) apresentou um bom ajuste a uma equação polinomial do $2^{\circ}$ grau, tanto no ambiente natural quanto na câmara fria. Em ambiente natural, as plântulas mantiveram a sua massa seca inicial por um período de seis meses de armazenamento, apresentando uma queda drástica aos 24 meses. De forma semelhante à encontrada por Corvello et al. (1999) em cedro, em que as sementes armazenadas em ambiente natural mantiveram o mesmo peso de matéria seca durante seis meses, com tendência ge- ral de redução entre seis e doze meses de armazenamento. A variação da massa seca da plântula nas sementes armazenadas em câmara fria foi de menor magnitude do que no ambiente natural. Na mesma espécie, Teófilo et al. (2003) observaram que os valores da matéria seca da plântula mantiveram-se inalterados durante três períodos de armazenamento (3, 6 e 9 meses), tanto em ambiente natural como em câmara fria.

Examinando-se a Figura 3, constata-se que houve uma resposta linear e crescente da condutividade elétrica em função do tempo de armazenamento. Resposta similar foi encontrada por Freitas et al. (2000) em sementes de algodão (Gossypium hirsutum L.) acondicionadas em sacos de papel e armazenadas em ambiente natural durante cinco épocas ( $0,3,6$ e 12 meses). Esse comportamento denota que quanto mais tempo as sementes de moringa permanecerem estocadas, mais há um aumento da permeabilidade das membranas e, portanto, aumento da lixiviação de eletrólitos dos tecidos da semente para a água destilada na qual essa ficou imersa, correlacionando-se com o avanço na deterioração e a conseqüente redução no vigor, como relata Popinigis (1985).

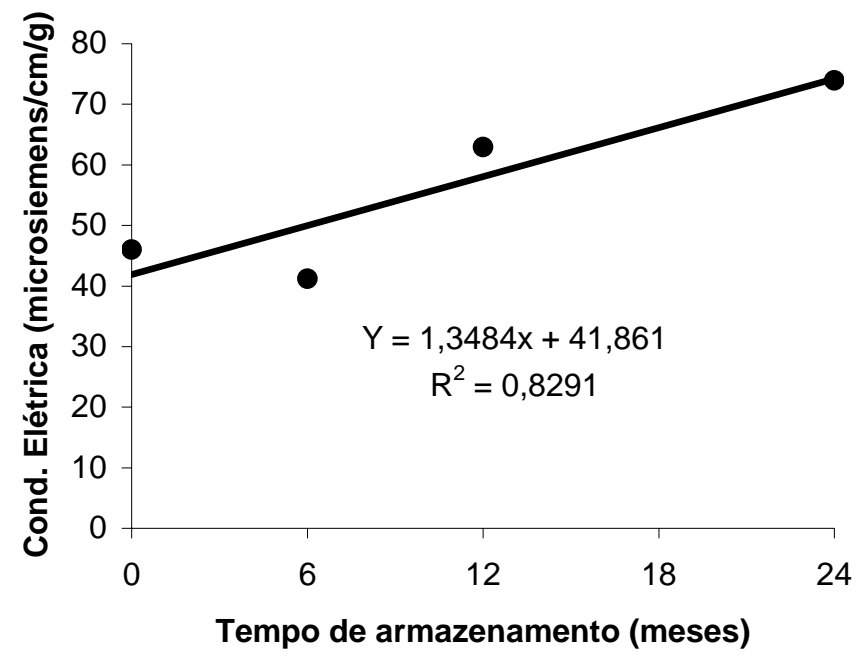

FIGURA 3 - Condutividade elétrica avaliada durante o armazenamento de sementes de moringa em ambiente natural e câmara fria. Fortaleza, UFC, 2003. 


\section{CONCLUSÕES}

As sementes de moringa mantêm o percentual de germinação por 12 meses; aos 24 meses, a redução da germinação foi de aproximadamente $15 \%$, quando armazenadas em condições de baixa temperatura $\left(10^{\circ} \mathrm{C}\right)$ e baixa umidade (55\% de UR);

As sementes armazenadas sob condições não controladas (alta temperatura e alta umidade) mantêm a sua qualidade inicial por seis meses, aos 12 meses a redução da germinação foi de $78 \%$, e aos 24 meses, de $100 \%$.

\section{AGRADECIMENTOS}

Ao Dr. Sérgio Horta Mattos e ao Prof. Renato Inecco, pelo fornecimento das sementes para realização da pesquisa.

\section{REFERÊNCIAS BIBLIOGRÁFICAS}

ARRIGONI-BLANK, M. F. et al. Armazenamento e viabilidade de sementes de Campomanesia rufa. Ciência e Agrotecnologia, Lavras, v. 21, n. 1, p. 85-90, 1997.

BRASIL. Ministério da Agricultura e Reforma Agrária. Regras para análise de sementes. Brasília: SNDA/DNDV/CLAV, 1992. 365 p.

CÁCERES, A. et al. Moringa oleifera (Moringaceae): etnobotanical studies in Guatemala. Economic Botany, [S.1.], v. 45, n. 4, p. 522-523, 1991.

COPELAND, L. O. Principles of seed science and technology. Minnesota: Burgess, 1976. 369 p.

CORREA, M. P. Dicionário das plantas úteis do Brasil e das exóticas cultivadas. Rio de Janeiro, MA/IBDF, 1984. v. 5.

CORVELLO, W. B. V. et al. Época de colheita e armazenamento de cedro (Cedrela fissilis Vell.). Revista Brasileira de Sementes, Londrina, v. 21, n. 2, p. 28-34, 1999.

DELOUCHE, J. C. et al. Storage of seed in sub-tropical and topical regions. Seed Science and Technology, New Delhi, v. 1, n. 3, p. 671-700, 1973.

FERREIRA, P. V. Estatística experimental aplicada à agronomia. 2. ed. Maceió: EDUFAL, 1996. $606 \mathrm{p}$.
FREITAS, R. A. et al. Qualidade fisiológica e sanitária de sementes de algodão durante o armazenamento. Revista Brasileira de Sementes, Campinas, v. 22, n. 2, p. 94-101, 2000.

LALAS, S.; TSAKINS, J. Characterization of Moringa oleifera seed oil variety "Periyakulam 1". Journal of Food Composition and Analysis, [S.1.], v. 15, p. 6577, 2002.

LORENZI, H.; MATOS, F. J. A. Plantas medicinais no Brasil: nativas e exóticas cultivadas. Nova Odessa: Instituto Plantarum, 2002. 347 p.

MACEDO, E. C.; GROTH, D.; SOAVE, J. Influência da embalagem e do armazenamento na qualidade fisiológica de sementes de algodão. Revista Brasileira de Sementes, Campinas, v. 20, n. 2, p. 454-461, 1998.

MACHADO, L. S.; CARNEIRO, J. G. M. Semente de moringa: avaliação das farinhas integral e desengordurada, caracterização da fração lipídica e ação coagulante da farinha desengordurada sobre a água turva do Rio Poti. Teresina: UFPI, 2000. 13 p. Relatório final PIBIC/UFPI.

MATOS, F. J.; ABREU. Farmácias vivas: sistemas de utilização de plantas medicinais projetado para pequenas comunidades. 3. ed. Fortaleza: EUFC, 1998. $220 \mathrm{p}$

MEDEIROS FILHO, S. et al. Efeito do armazenamento sobre a qualidade fisiológica de sementes deslintadas de algodão. Ciência e Agrotecnologia, Lavras, v. 20, n. 3, p. 284-292, 1996.

NAKAGAWA, J. Testes de vigor baseados na avaliação das plântulas. In: VIEIRA, R. D.; CARVALHO, N. M. Testes de vigor em sementes. Jaboticabal: FUNEP, 1994. p. 49-85.

OLIVEIRA, J. T. A. et al. Compositional and nutritional attributes of seeds from the multiple purpose tree Moringa oleifera Lamarck. Journal of the Science of Food and Agriculture, London, v. 79, p. 815-820, 1999.

PÁDUA, G. P.; VIEIRA, R. D. Deterioração de sementes de algodão durante o armazenamento. Revista Brasileira de Sementes, Campinas, v. 23, n. 2, p. 255-262, 2001. 
PALANISAMY, V. et al. Influence of seed treatments and containers on the viability of annual moringa seeds. South Indian Horticulture, New Delhi, v. 43, n. 1-2, p. 42-43, 1985.

POPINIGIS, F. Fisiologia da semente. Brasília: AGIPLAN, 1985. 289 p.

RAMACHANDRAN, C.; PETER, K. V.; GOPALAKRISHNAN, P. K. Drumstick (Moringa oleifera) a multipurpose Indian vegetyable. Economy Botany, [S.l.], v. 34, p. 276-283, 1980.
SILVA, A. R.; KERR, W. E. Moringa: uma nova hortaliça para o Brasil. Uberlândia: UFU/DIRIU, 1999. 95 p.

TEÓFILO, E. M. et al. Efeito dos tipos de embalagem, ambiente e tempo de armazenamento na qualidade fisiológica das sementes de moringa (Moringa oleifera Lam.) - Moringaceae. Revista Científica Rural, Bagé, v. 8, n. 1, p. 115-122, 2003.

VIEIRA, R. D.; KRZYZANOWSKI, F. C. Teste de condutividade elétrica. In: VIEIRA, R. D.; FRANÇANETO, J. B. F. (Eds.). Vigor de sementes: conceitos e testes. Londrina: ABRATES, 1999. cap. 4, p. 1-26. 